\title{
Queensland solar feed-in tariffs and the merit-order effect: economic benefit, or regressive taxation and wealth transfers?
}

\author{
Tim Nelson, Paul Simshauser and James Nelson* \\ Level 22, 101 Miller Street \\ North Sydney, NSW, 2060. \\ February 2012
}

\begin{abstract}
Premium residential solar feed-in tariffs have come under considerable scrutiny in Australia over the past 12 months following a sharp rise in the uptake of subsidised PV units and subsidy cost blow-outs. Using New South Wales data, Nelson, Simshauser and Kelley (2011) demonstrated that the inherent design of premium 'gross' feed-in tariffs are regressive in nature and required reform. Since the publication of that article in Economic Analysis \& Policy (September 2011 edition), feed-in tariff policies have been substantially wound back in all Australian jurisdictions except Queensland. In this article, we examine the 'net' feed-in tariff in Queensland and similarly find it to be a regressive form of taxation. We also examine the so-called 'merit order effect' - a purported 'economic benefit' arising from premium feed-in tariffs. However, the evidence is clear that merit order effects must, by definition, be transient and above all, are not welfare enhancing.
\end{abstract}

Keywords: Feed-in Tariffs, Electricity Prices, Merit Order Effect. JEL Codes: D61, L94 and Q48.

\section{Introduction}

In Australia's National Electricity Market, there has been a truly rapid uptake of small-scale solar photovoltaic (solar PV) systems on household rooftops in recent years. In 2007, the cumulative installation of solar PV systems was just $9600 \mathrm{~kW}$, or $9.6 \mathrm{MW}$, set within a roughly $50,000 \mathrm{MW}$ power grid. By 2011, installations had increased to $1031 \mathrm{MW}$, a more than 100-fold in just four years (CEC, 2011). While there have been very substantial declines in the unit costs of smallscale solar PV systems, crucially, this extraordinary growth has been pump-primed by what has been widely acknowledged as excessively generous subsidies provided by multiple levels of government.

Upfront capital grants were initially used to stimulate demand. But the primary mechanism by which solar PV has been incentivised has been through the introduction of 'premium' solar feedin tariff policies. As we later reveal, premium feed-in tariffs were paid at the rate of $\$ 440$ $\$ 600 / \mathrm{MWh}$, depending on the jurisdiction. To put the extent of the premium or subsidy into context, households are only charged about $\$ 200 / \mathrm{MWh}$ for power drawn from the electricity grid. It is also worth noting that the economic value of roof-top PV output, which equates to the opportunity value of that power, was found by a recent regulatory inquiry to be within the range of $\$ 52$ - \$103/MWh (IPART, 2012). Feed-in tariffs of \$440-\$600/MWh, therefore, represent a very substantial subsidy indeed.

Some solar PV advocates have argued that small-scale units should be afforded a 'grid parity' price, that is, c. $\$ 200 / \mathrm{MWh}$. This is, however, not correct. It can be demonstrated that solar PV units avoid the wholesale cost of power generation (albeit on a discounted basis due to inherent

- Tim Nelson is Head of Economic Policy \& Sustainability at AGL Energy Ltd. He is also an Adjunct Research Fellow at the University of New England. Paul Simshauser is Chief Economist at AGL Energy Ltd and Professor of Finance at Griffith University. James Nelson is an energy market analyst at AGL Energy. The authors are grateful to the Bureau of Resource \& Energy Economics Chief Economist, Quentin Grafton, Rajat Sood from Frontier Economics, and Cameron Reid from AGL Energy Ltd for their insightful comments on earlier drafts. However, any remaining errors or omissions remain entirely the responsibility of the authors.

Correspondence should be directed to Tim Nelson at tanelson@agl.com.au 
variability and therefore uncertainty of production output), the carbon price, proportional electrical losses on the network, and a case can be made for avoiding some small component of transmission and distribution network charges. Although in relation to the latter, as Figure 4 and Appendix I later reveal, output from solar PV units is trivial during critical peak demand periods. Since critical peak demand events are the key driver of network augmentation costs and therefore network tariff settings, no material reduction in network costs is likely to arise from solar PV units (IPART, 2012). In essence, households with solar PV units will remain fundamentally reliant on the network for a reliable energy supply. And the fact that solar PV units qualify for an export tariff does, by definition, demonstrate that rooftop solar units make use of the low-voltage Distribution Network to export surplus power to the grid. Additionally, energy retailers are responsible for providing billing services for PV exports and managing the residual energy requirements of solar PV customers, and thus the costs of the distribution network and of energy retailers are not avoided costs. These costs typically represent more than half of the delivered price of power.

Most problematic is the funding source of feed-in tariff subsidies, viz. all electricity consumers. Premium solar feed-in tariffs require electricity distribution network owners to levy all 8 million households with an additional charge for using the grid. These funds are then re-channelled back to the roughly 695,000 households who own solar PV units. ${ }^{1}$ Nelson, Simshauser and Kelley (2011) found that in the case of New South Wales, solar PV owners tended to be comparatively wealthy home-owners, and the very private benefits of the units were comprehensively and unambiguously internalised by the participating households. In contrast, low income and rental households incur the costs without receiving any visible benefit. In addition, since the charge to all households is based on electricity usage and not income, the cost recovery process was found to be highly regressive, with low income households paying an effective tax incidence that was 2.7 times the rate paid by high-income households.

In setting out their analysis, Nelson, Simshauser and Kelley (2011) established three criteria for analysing the efficiency and equity of premium solar PV feed-in tariffs. These were (1) funding sources should come from equitable sources to cover the subsidy costs of feed-in tariffs, (2) policy settings should be anti-cyclical in terms of solar PV industry development, and (3) feed-in tariffs should reasonably reflect any avoided network investment costs. They concluded that when "assessed against the three core criteria, it is apparent that current feed-in tariff policies are suboptimal. There is considerable room for progress towards improvement, firstly through better institutional arrangements, secondly through structuring the tariff, and of course identifying more appropriate (i.e. progressive) funding sources for ongoing feed-in tariff schemes" (Nelson, Simshauser and Kelley, 2011, p.128).

Since publication of Nelson, Simshauser and Kelley (2011) in the September Quarter edition of Economic Analysis \& Policy ${ }^{2}$, a number of material public policy developments have occurred. Feed-in tariffs have been substantially wound back in New South Wales, Victoria and South Australia due to concerns by policymakers about the proliferation of system installations and the associated cost impacts of recovering the subsidy through headline electricity tariffs. Only Queensland has retained its feed-in tariff policy.

Perhaps not surprisingly, the winding back of premium feed-in tariff policies has generated considerable public commentary. Some solar PV advocates have argued that a purported economic benefit of solar PV has been substantially ignored by energy economists - the so-called 'merit order effect' ${ }^{3}$ - that is, the downward pressure that the deployment of renewable resources

\footnotetext{
${ }^{1}$ Data from ORER at http://www.orer.gov.au/REC-Registry/Data-reports. Accessed 1 February 2012.

${ }^{2}$ An earlier draft of Nelson, Simshauser and Kelley (2011) was made available and circulated amongst industry analysts and policymakers in March 2011.

${ }^{3}$ See Parkinson $(2011,2012)$ for examples of the purported benefits of the merit-order effect.
} 
places on wholesale energy prices. Certainly Nelson, Simshauser and Kelley (2011) did not contemplate the 'merit order effect'.

The purpose of this article is therefore twofold. First, we analyse the extent to which Queensland's feed-in tariff policy is a regressive form of taxation. Second, we examine the principle argument raised by solar PV advocates in support of premium feed-in tariffs, viz. the 'merit-order effect'. Specifically, we analyse whether it produces any genuine economic benefits. By examining these issues together, policymakers in Queensland will be better placed to assess whether the existing feed-in tariff policy should be continued, or wound back in a similar fashion to other National Electricity Market jurisdictions.

This article is structured as follows: In Section 2, we provide an update on the Australian policy environment in relation to premium residential solar PV feed-in tariffs. Quantitative evidence is presented in Section 3 to assess the existing QLD feed-in tariff policy against the criteria public policy criteria outlined in Nelson, Simshauser and Kelley (2011). Section 4 then outlines recent public commentary about purported economic benefits of solar PV and critically analyses the arguments. Our policy recommendations and concluding remarks follow.

\section{An update on the Australian public policy environment in relation to feed-in tariffs}

Australian public policy has been very successful at driving the uptake of non-utility scale, residential solar PV units. Prior to 2007, very few policy measures were in place to stimulate the demand for the residential PV unit. But from 2008, a virtual portfolio of policy measures were introduced that, in hindsight, were too successful at incentivising households to purchase and install solar PV systems from a subsidy cost perspective. These included capital grants and premium feed-in tariffs. The growth in cumulative installed capacity of small scale solar PV units in Australia is shown in Figure 1.

Figure 1: Cumulative installed capacity of small scale solar PV in Australia

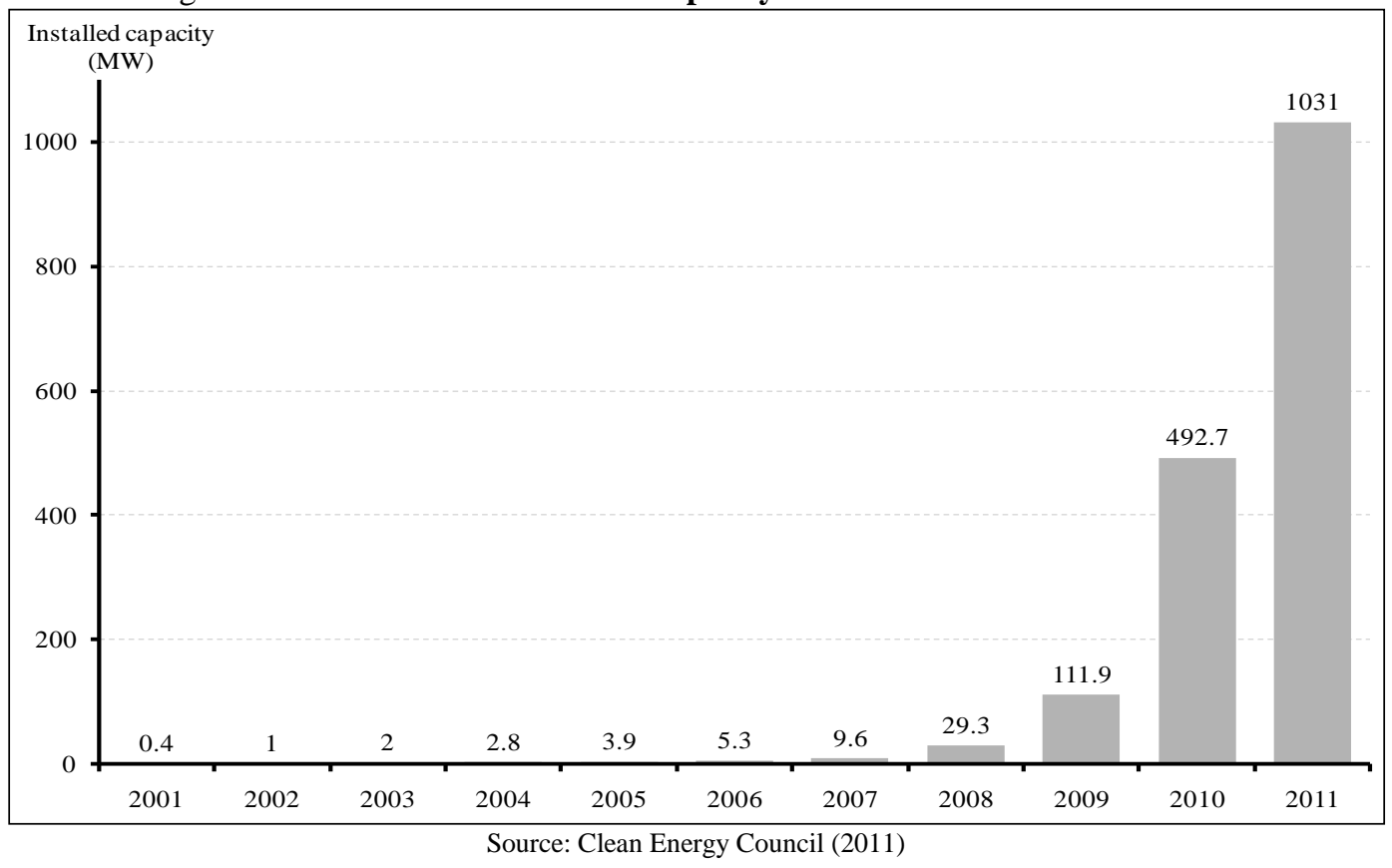

Figure 1 illustrates what can only be described as explosive growth in residential solar PV installations during 2009 - 2011. Between 2007 and 2011, the cumulative installed capacity of these units in Australia increased 100-fold, from about 10MW to more than 1000MW. There is little doubt that this extraordinary growth was due to the premium feed-in tariff incentives available from 2009. Table 1 outlines the various feed-in tariff policies, their duration, and an 
approximate payback period for a customer that installed a solar PV unit in 2010 using the cost data from Nelson et al (2011).

Table 1: Feed-in tariff policies in place during 2010

\begin{tabular}{ccccc}
\hline State & Max size & Rate $\$ /$ MWh & Duration & Approximate pay-back period ${ }^{4}$ \\
\hline Vic & $5 \mathrm{~kW}$ & $\$ 600($ net $)$ & 15 years & 6.5 years \\
SA & $30 \mathrm{~kW}$ & $\$ 540($ net) & 20 years & 7.5 years \\
NSW & $10 \mathrm{~kW}$ & $\$ 600$ (gross) & 7 years & 2 years \\
QLD & $30 \mathrm{~kW}$ & $\$ 440($ net) & 20 years & 9 years \\
ACT & $30 \mathrm{~kW}$ & $\$ 450$ (gross) & 20 years & 2.5 years \\
\hline \multicolumn{5}{c}{ Source: AGL Energy Ltd. }
\end{tabular}

Utility-scale power generating equipment typically has a useful life of 25-40 years, and a payback period in the order of 18-29 years, respectively (Nelson, 2011). This is in stark contrast to the pay-back periods outlined in Table 1 for non-utility scale PV units, which also have a useful life of about 25 years (and by implication, one might reasonably expect a payback period of about 18 years given utility-scale results). The most obvious sign of the unsustainable nature of the premium feed-in tariff policies that existed from 2009 was that in all instances, the payback period (i.e. the point in time at which all upfront costs are recovered through the feed-in tariff) occurs before half of the feed-in tariff revenue is received from government-mandated schemes, and after only a small fraction of the unit's useful life. Households that installed a solar PV unit will receive substantial profits, paid for and at the expense of, all other electricity consumers.

While it is unsurprising that installations have been most numerous in New South Wales given its large population and the extremely short payback period, it is surprising that installation rates in South Australia and Queensland have been more prolific on a per household basis. Figure 2 illustrates the installed capacity of residential solar PV units by jurisdiction over the 2009-2011 period measured by the bar charts on the left-hand-side y-axis. The diamond-shaped markers measured on the right-hand-side y-axis plot the average installed capacity of solar PV per household in each jurisdiction. South Australia has the highest proportional installed capacity at $0.28 \mathrm{~kW}$ per household.

Figure 2 notes that about $400 \mathrm{MW}$ of new solar PV capacity was installed in Queensland over the period 2009-2011. The long tail of payments, which runs for 20 years, makes installation incredibly attractive from an economic perspective. This has important and yet unappreciated consequences for Queensland policymakers. While the costs of the New South Wales feed-in tariff policy are substantial, they are also comparatively short-lived with all payments ceasing after seven years. However, in Queensland and South Australia, the costs of the policy, which are spread across all energy consumers, are 'locked-in' for 20 years.

\footnotetext{
${ }^{4}$ The payback period is based upon capital costs being incurred upfront minus RECs with revenue accruing as per the methodology in Nelson, Simshauser and Kelley (2011). As capital costs for solar systems have evolved (both due to underlying changes to cost structures and exchange rate appreciation), payback periods may be shorter than indicated in Table 1. 
Figure 2: $\quad$ Annual solar PV installations by State

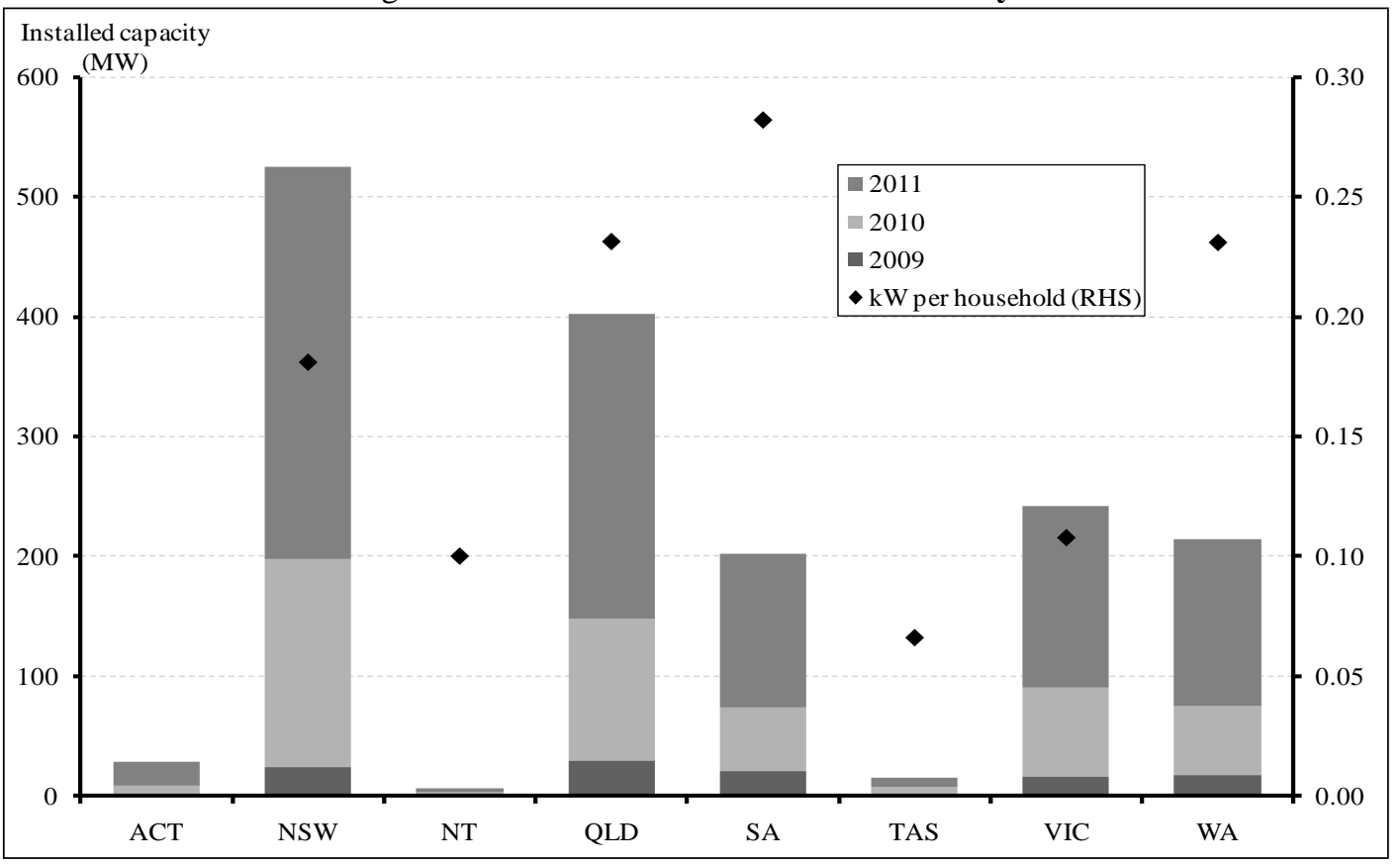

Source: Clean Energy Council (2011), esaa (2011), AGL Energy Ltd.

During 2011, feed-in tariff policies have been wound back considerably by jurisdictional policymakers with the exception of Queensland. Specific actions taken by policymakers have included:

- $\quad$ New South Wales: the gross feed-in tariff was initially reduced from $\$ 600$ to $\$ 200 / \mathrm{MWh}$ in late-2010 when a legislated $50 \mathrm{MW}$ aggregate installation cap was anecdotally reached. The New South Wales Government then announced in early-2011 that the feed-in tariff policy would be 'closed' to any future household when $300 \mathrm{MW}$ of aggregated capacity was installed. Following a change of government in March 2011, the policy was revoked and at one point, the newly appointed government sought to retrospectively reduce all prior government policy commitments to existing PV owners from $\$ 600 / \mathrm{MWh}$ to $\$ 400 / \mathrm{MWh}$. However, the widespread public backlash neutralised the government's ability to implement a retrospective policy change. ${ }^{5}$ Instead, an independent regulatory review was commissioned and concluded that the fair and reasonable value for any feed-in tariff is $\$ 52$ - \$103/MWh for new installations, but that feed-in tariffs should not be mandatory (IPART, 2012).

- $\quad$ South Australia: legislative changes took effect from 29 July 2011. The impact of this change to the legislative framework was to reduce the net feed-in tariff payable from \$540/MWh to $\$ 160 / \mathrm{MWh}$ for five years for new installations of solar PV from 1 October 2011. In addition, the South Australian Government has legislated that beyond 30 September 2013, no mandated feed-in tariff will be payable for new installations.

- Victoria: the government closed its feed-in tariff to new applications after reaching a nominal $100 \mathrm{MW}$ capacity limit in 2011. A transitional net feed-in tariff was introduced from January 2012, paid at $\$ 250$ / MWh for five years. Only systems under 5kW are

\footnotetext{
${ }^{5}$ Many households in New South Wales committed to solar PV units on the basis of the original gross feed-in tariff policy presented to them at the time by the State Government. In a number of cases, households arranged bank finance to fund the requisite upfront investment, with the terms of the finance matching the expected benefits. While we do not support premium feed-in tariffs, neither would we suggest retrospective changes to feed-in tariffs on the grounds of sound public policymaking (and perceptions of 'regulatory risk').
} 
eligible to receive the transitional tariff. The Victorian Government has also commissioned a regulatory review of feed-in tariff policy. The Victorian Competition and Efficiency Commission will provide recommendations on whether to phase-out or change feed-in tariff policies in that state.

- $\quad$ Australian Capital Territory: the territory government closed its feed-in tariff policy scheme on 13 July 2011.

- Western Australia: while not part of the National Electricity Market, it is worth noting that the government reduced the feed-in tariff payable from $\$ 400 / \mathrm{MWh}$ to $\$ 200 / \mathrm{MWh}$ from 1 July 2011. However, only a few months later the entire scheme was suspended. At the time of writing there is no mandated feed-in tariff for new installations in Western Australia.

Table 2 summarises the current feed-in tariff framework in all Australian mainland jurisdictions. Two particular trends seem to have emerged: (1) feed-in tariff policies are gradually being suspended or abolished; and (2) feed-in tariff policies have been redesigned to ensure that payback periods occur after the mandated tariff ceases to apply.

Table 2: Mandated feed-in tariff policies in place as at January 2012

\begin{tabular}{cccc}
\hline State & Rate $\$ / \mathrm{MWh}$ & Duration & Approximate pay-back period \\
\hline Vic & $\$ 250($ net $)$ & 5 years & Beyond mandated tariff \\
SA & $\$ 160($ net) & 5 years & Beyond mandated tariff \\
NSW & None $^{7}$ & N/A & N/A \\
QLD & $\$ 440($ net $)$ & 20 years & 9 years \\
WA & None & N/A & N/A \\
ACT & None & N/A & N/A \\
\hline
\end{tabular}

With the exception of Queensland, it would seem that policymakers have acknowledged the adverse consequences of feed-in tariff policies identified in Nelson, Simshauser and Kelley (2011). Thus at this point it is appropriate to analyse the Queensland scheme.

\section{An analysis of Queensland's feed-in tariff policy}

As at the time of writing, the Queensland Solar Bonus Scheme mandates that energy retailers pay \$440/MWh to households with solar PV units for all surplus electricity supplied to the electricity grid (i.e. it is a 'net' feed-in tariff because only surplus power exported to the grid is paid the premium price). This price is considerably higher than the approximately $\$ 200 / \mathrm{MWh}$ tariff paid by households when they consume energy from the main electrical grid. Under the Electricity Act 1994, feed-in tariff payments cease in the year 2028. This feed-in tariff will therefore remain in place for the $400 \mathrm{MW}$ of solar PV units that have now been installed in Queensland.

Given the virtual retirement of feed-in tariff policies in other jurisdictions, we believe our analysis is timely because Queensland is the last jurisdiction to offer a premium subsidy to new

\footnotetext{
${ }^{6}$ The payback period is based upon capital costs being incurred upfront minus RECs with revenue accruing as per the methodology in Nelson, Simshauser and Kelley (2011)

${ }^{7}$ As noted earlier, IPART (2012) has recommended the fair and reasonable value of solar PV feed-in tariffs is $\$ 52-\$ 103 / \mathrm{MWh}$, but recommended against a 'mandatory' offer.
} 
installations and so one might reasonably assume that the marketing efforts of installers will be more concentrated - with the ensuing market velocity ${ }^{8}$ presumably accelerating as a result.

To assess the effectiveness, efficiency and equity of Queensland feed-in tariffs, we have utilised the same criteria established in Nelson et al (2011), viz.:

- $\quad$ The funding for feed-in tariffs should be derived from an equitable source: small-scale renewable stimulus policies result in very private benefits that are comprehensively and unambiguously internalised by the participating household. As such, the fairness of the policy should be based upon whether its funding method is progressive or regressive in nature.

- $\quad$ Anti-cyclical long-term industry development: solar PV activity presumably offers benefits beyond renewable energy production and to that end, stimulating industry development may well be a justifiable policy objective. If this is the case, policy settings should be designed to facilitate smooth industry growth and accommodate predictable changes in technology costs and price movements in the energy sector, including a future price on carbon. We distinguish this from policies built on unsustainable subsidies that become pro-cyclical and ultimately cause a boom-and-bust scenario for solar PV installers. As Figure 3 later reveals, unfortunately, policy settings internationally (and in Australia) have been demonstrably pro-cyclical.

- $\quad$ Capture of potential distributed generation benefits: the structure of a feed-in tariff should capture any benefits of reduced network congestion or augmentation reasonably delivered by distributed generation.

\subsection{Equitable source of funding for feed-in tariff subsidies}

The economic literature clearly describes feed-in tariff policies as outsourced forms of taxation, whereby the costs of State Government policy are recovered from electricity consumers in proportion to how much electricity they use, irrespective of household income. We have utilised the methodology in Nelson et al (2011) to determine whether this outsourced form of taxation in Queensland is regressive or progressive in nature.

To begin with, we have assumed that the $\$ 440 / \mathrm{MWh}$ feed-in tariff is paid for $30 \%$ of the output produced (i.e. $30 \%$ being a surrogate for net household production, given Queensland has a net feed-in tariff). We assume the solar PV unit accrues the benefits of the net feed-in tariff for 18 years from 2011. Equation 4.1 outlines the total number of systems (TS) installed and their rated capacity in 2010 and 2011. Our data has been sourced from CEC (2011) and we assume that all systems are $1.5 \mathrm{~kW}$ in size, noting that some larger and wealthier households have no doubt installed much larger units:

$T S_{20102011}=\frac{373.7 M W}{1.5 k W / 1000}=249,146$ systems installed

Each $1.5 \mathrm{~kW}$ is assumed to produce $2.25 \mathrm{MWh}$ of electricity annually. ${ }^{9}$ The total energy output (SO) of these installed systems in year $y$ expressed in MWh is presented in Equation 4.2:

$S O_{y}=249,146$ units $* 2.25 M W h=560,579 M W h$

${ }^{8}$ We use the term 'market velocity' to describe the rate solar PV installation sales.

${ }^{9}$ Figures obtained from SGU calculator (https://www.rec-registry.gov.au/sguCalculatorInit.shtml) accessed in January 2012 
The total costs (TC) of the Queensland feed-in tariff policy paid over 18 years to the year 2028 can therefore be expressed as outlined in Equation 4.3:

$$
T C=P V \sum_{y}^{18} S O_{y} * \text { Tariff } * 0.3=P V \sum_{y}^{18} 560,579 * \$ 440 * 30 \%=\$ 1.062 \text { billion }
$$

Assuming that the output exported to the grid is based upon a fair value of energy, the total cost in 2011 of all output would be $\$ 13.0$ million using the midpoint of the IPART (2012) estimate of $\$ 52$ - \$103/MWh. However, the annual payments to households with a solar PV unit equates to $\$ 74.0$ million because the feed-in tariff is set to $\$ 440 / \mathrm{MWh}$, not $\$ 77.50 / \mathrm{MWh}$ (see Equation 4.3 for year y). Accordingly, $82 \%$ of the value paid to households with solar PV units represents a direct wealth transfer. Using Equation 4.3, of the $\$ 1.062$ billion in costs, $\$ 978$ million are wealth transfers from grid connected consumers to installers of solar PV systems. Such analysis is in itself indicative of a substantially regressive policy outcome as the primary eligibility criteria for installation is ownership of a dwelling (i.e. a barrier to entry for vulnerable, low-income, and rental households).

We can also calculate the impact on final electricity tariffs to consumers by dividing Total Costs TC by aggregate electricity consumption in Queensland. Based upon esaa (2011) aggregate consumption data of $47,400 \mathrm{GWh}$ and annual costs of $\$ 74.0$ million, the impact on electricity prices will be $\$ 1.56 / \mathrm{MWh}$ under the Queensland policy during 2011 and 2012. To put this into context, power prices in Queensland increased by about \$14/MWh in 2011. The wealth transfer associated with the solar PV policy effectively made up almost $1 \%$ of the residential electricity tariff in 2011, and accounted for 10\% of the overall 2011 increase.

This is the headline impact. The impact on individual consumers on the other hand is a function of both the increase in price and their individual consumption of electricity. To analyse the impact on individual consumer segments, we have made use of the household survey data collated by Energex (2010). Table 3 outlines the total number of residential customers within various income groupings based upon the nearly 1.8 million households in Queensland. ${ }^{10}$

Table 3: Number of Queensland households by income and consumption groupings

\begin{tabular}{cccccc}
\hline $\begin{array}{c}\text { Household Income } \\
\text { (before tax) }\end{array}$ & $<4 \mathrm{MWh}$ & 4-6 MWh & $6-8 \mathrm{MWh}$ & $8-12 \mathrm{MWh}$ & $12 \mathrm{MWh}+$ \\
\hline up to $\$ 30,999 \mathrm{pa}$ & 81,813 & 89,994 & 76,904 & 45,815 & 14,726 \\
$\$ 31,000$ to $\$ 70,999$ & 96,539 & 147,263 & 168,534 & 142,354 & 37,634 \\
$\$ 71,000$ to $\$ 150,999$ & 68,723 & 111,265 & 152,171 & 173,443 & 71,995 \\
Greater than $\$ 151,000$ & 6,545 & 6,545 & 17,999 & 21,271 & 29,453 \\
Not disclosed & 39,270 & 55,633 & 53,996 & 68,723 & 17,999 \\
\hline
\end{tabular}

Source: Energex (2010)

The distribution of consumption across income groupings provides useful insights into different household cohorts within Queensland. As noted in Felder (2010) and in Nelson et al. (2011), there is a correlation between household income and electricity consumption. However, it is not a perfect correlation and this should be of concern to policymakers. More than $40 \%$ of lowincome households consume at least the average annual level of electricity, while $20 \%$ use substantially more than the Queensland average of $7 \mathrm{MWh}$ per annum (Simshauser, Nelson and Doan, 2011a). This has significant implications in relation to 'who pays' for the Queensland feedin tariff policy.

${ }^{10}$ Number of households sourced from Queensland Government, see http://www.oesr.qld.gov.au/products/publications/householddwel-proj-qld-lga/household-dwel-proj-qld-lga-2010.pdf. 
To analyse the effective incidence of outsourced taxation, weighted by consumption and income bracket, we have established weighted average annual costs per household, per income bracket, which are presented in Table 4.

Table 4: Impacts of Queensland Feed-in Tariff on Bills and Implied Tax Rates

\begin{tabular}{c|cc}
$\begin{array}{c}\text { Household Income } \\
\text { (before tax) }\end{array}$ & $\begin{array}{c}\text { Weighted } \\
\text { Average Cost } \\
\text { Per Household }\end{array}$ & $\begin{array}{c}\text { Implied } \\
\text { Outsourced } \\
\text { Taxation Rate } \\
\text { (median) }\end{array}$ \\
\hline$<\$ 30,999$ pa & 83.39 & 0.269 \\
$\$ 31,000-\$ 70,999$ & 93.25 & 0.183 \\
$\$ 71,000-\$ 150,999$ & 102.89 & 0.093 \\
$>\$ 151,000$ & 121.38 & 0.080 \\
Not disclosed & 96.32 & N/A \\
\hline
\end{tabular}

Based upon the results presented in Table 4, there is a correlation between the weighted average cost per household and household income, but the incremental costs are materially smaller than increases in income. Accordingly, the implied incidence of the cost tends to be inversely correlated with income. Alternatively put, the Queensland feed-in tariff policy is highly regressive in nature. In fact, the implied rate of taxation for low income households $(0.269 \%)$ is 3.4 times higher than those households in the highest income bracket $(0.080 \%) .{ }^{11}$ Surprisingly, the intensity of this result is worse than the New South Wales gross feed-in tariff policy analysed in Nelson, Simshauser and Kelley (2011), in which low income households faced an implied tax rate of 2.7 times the rate of higher income brackets.

If the Queensland feed-in tariff policy was funded through capital grants to households, with that funding being sourced from Commonwealth Government income tax revenue, the policy would be progressive in nature. But the existing regressive form of indirect taxation is a very poor policy outcome in that the benefits accrued from such policy are internalised by the wealthy households and lead to a disproportionately higher effective taxation rate on lower income households.

There is, however, a specific issue with the Queensland policy that requires special consideration. As we noted earlier, a clear difference between the Queensland policy and other (now defunct) policies of other states is the much longer timeframe over which the feed-in tariff payments are 'locked-in' by way of legislation. While the costs of the New South Wales scheme are greater, they are truncated over a shorter timeframe. In the case of Queensland, existing government policy is effectively locking-in a long-term wealth transfer from electricity consumers to solar PV owners until the year 2028. Electricity prices are currently rising for a range of reasons as Simshauser, Nelson and Doan (2011a) have previously highlighted. ${ }^{12}$ Queensland policymakers should therefore consider closing the existing policy to new entrants to ensure that long-term wealth transfers do not accelerate further, and replacing it with a more sustainable tariff structure.

3.2 Long-term stability for the development of solar PV industry capacity Nelson et al (2011) identified that net feed-in tariff policy structures, such as those in Queensland, are better equipped to provide stable industry development as payback periods are more measured than those for gross feed-in tariffs, such as those that existed in New South Wales and the

\footnotetext{
${ }^{11}$ As outlined in Nelson et al (2011), the regressive nature is probably understated due to the electricity load in higher income households being lower due to their electricity needs being met by solar PV systems. This results in less costs being incurred by these higher income households with lower income households funding the difference

${ }^{12}$ The drivers of higher electricity prices include rising fuel costs, capital costs and cost of capital, higher network capital expenditure in response to rising peak demand, and environmental policies. 
Australian Capital Territory. Installers are generally able to lock in long-term contracts both in relation to purchasing systems and selling them to consumers. However, the analysis in Section 2 indicates that the Queensland tariff has a payback period which is half the timeframe over which the tariff is paid. This is unsustainable, and will eventually lead to a 'bust scenario' when policy makers inevitably wind back the policy to prevent any further cost blowouts in the wealth transfers identified in Section 3.1. If our earlier logic is correct - that the marketing efforts of various solar PV installers begins to concentrate on Queensland, and that the market velocity intensifies due to scheme closures and wind-backs in other states - the better view would be for policymakers to act early and before any further overheating occurs in the supplier market.

To be sure, an intensifying market velocity followed by an installer market collapse (due to predictable scheme closure) is far more than a theoretical possibility. Around the world, governments have introduced excessively generous feed-in tariff policies which have stimulated unsustainable growth in solar PV installations. They have then been substantially wound back or closed once the subsidy costs have been revealed. In Figure 3, we illustrate the highly unstable and pro-cyclical 'boom-bust' cycle that accompanies premium feed-in tariff policies from various international markets.

Figure 3: $\quad$ PV installations relative to maximum year in various international jurisdictions

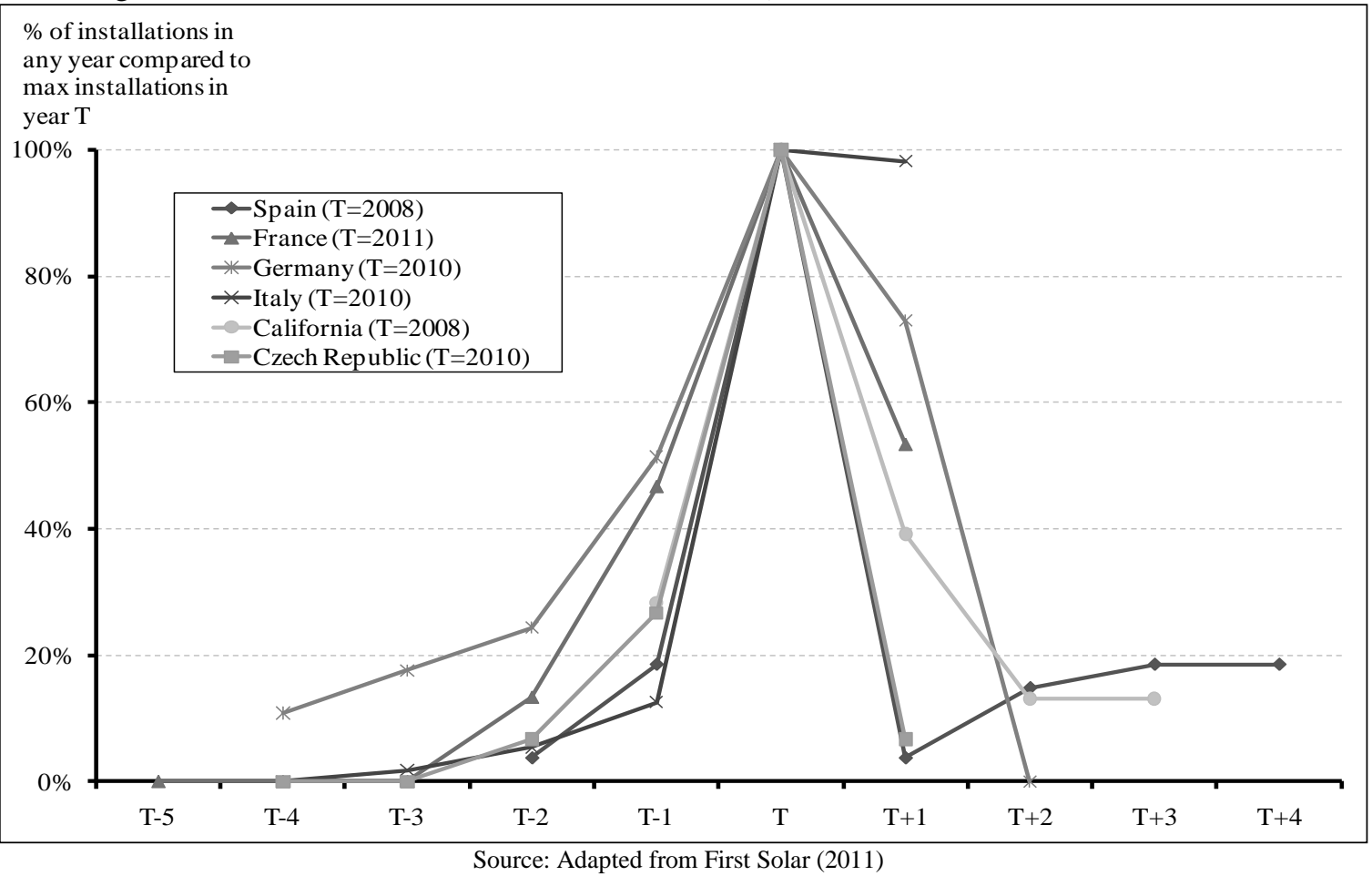

The data in Figure 3 has been drawn from the small-scale solar PV markets in Spain, France, Germany, Italy, California and the Czech Republic. Time in years is listed on the x-axis and aggregate annual installed capacity is measured on the y-axis. Note that each market is characterised by an 'event' signified by 'Year T' - the year that the premium feed-in tariff, consumer surplus and wealth transfers, reach their maximum. Year $\mathrm{T}$ is also, by definition, the point at which the feed-in tariff reaches its most unsustainable point, and soon after is varied by policymakers.

What is clear from Figure 3 is that premium feed-in tariffs produce an acute business cycle. The cycle is evident across all jurisdictions and is consistent with the Australian experience summarised in Section 2. The origins of the event in time $\mathrm{T}$ can be traced back to policymakers 
introducing a pro-cyclical ${ }^{13}$ premium feed-in tariff, which on average seems to occur in 'Year T2'. The market then responds, and the take-up rates of solar PV installations increases exponentially. After two years of activity, the unexpected market expansion causes unforeseen cost blowouts of the feed-in tariff policy. The cost blowout is revealed through the requisite raising of electricity prices to all consumers to cover program costs, which is invariably accompanied by highly adverse media and criticism by welfare groups. Policymakers, quite understandably, react rapidly by reducing or eliminating feed-in tariffs to new entrants.

While the initial reactionary response by policymakers is necessary, it is also typically instigated with ruthless speed given the velocity of solar PV markets under premium feed-in tariffs. This then creates a second round of impacts - collapsing solar PV installation businesses, and a second round of adverse media and criticism by solar and environmental advocacy groups. Few would disagree that this cycle reflects the New South Wales 'installer boom-bust' scenario of 20092011. The consistency of market results displayed in Figure 3, and the magnitude of the cycle must surely make for sobering reading to any policymaker, let alone solar PV premium feed-in tariff advocates.

To adequately address the criteria of 'long-term stability for the development of solar PV industry capacity', policymakers should ensure that installers of solar PV systems receive a 'fair value' for the energy produced by PV systems, and be sure to avoid substantial wealth transfers from existing electricity consumers to households that install solar PV units.

This approach was eventually adopted by the New South Wales Government in its regulatory review of solar PV feed-in tariff policy. The Terms of Reference for the review require the Independent Pricing and Regulatory Tribunal to identify the 'fair and reasonable value' that should be paid by energy retailers for output from solar PV systems without increasing other gridconnected customer's electricity bills (O'Farrell, 2011).

\subsection{Structuring feed-in tariffs to capture network benefits}

At the time of publication, Nelson et al (2011, p.127) stated that: “...we are not aware of any analysis by policymakers addressing the question of whether distributed solar PV systems provide network benefits..." We presume this observation still holds in relation to Queensland's feed-in tariff policy. The ratio of peak demand to underlying or base energy demand in Queensland is currently about 113\% (Nelson, Kelley, Orton and Simshauser, 2010). The result of this growth differential is a worsening utilisation rate of electricity equipment, and a rise in capital expenditure (which in turn inflates headline electricity tariffs).

Other policy makers have begun to consider this issue. In its current regulatory review of feed-in tariff policy, the New South Wales Government has required the Independent Pricing and Regulatory Tribunal to consider "...the impact of small-scale solar PV, if any, on the costs of network distribution businesses, including capital and operating costs..." (O'Farrell, 2011). Importantly however, the evidence provided by distribution network companies thus far seems to indicate that the benefits of small-scale PV units in relation to avoiding or deferring network congestion and augmentation are negligible.

Figure 4 outlines evidence submitted by Endeavour Energy, owner and operator of a large distribution network in New South Wales. The Figure shows that while solar PV output is positively correlated to demand, it makes a only a trivial contribution during the critical peak period at 5:30pm - the point in time that fundamentally drives network augmentation. In its submission to the review, Endeavour Energy (2011, p.2) observed that:

${ }^{13}$ The term pro-cyclical is used to describe the effects of the design of feed-in tariff policy, that is due to the 'excessive' level of tariffs in the upswing of the market (up to year T). 
... since substation capacity is sized on network peak demand, it can be said that residential solar PV without battery storage had negligible benefits in reducing the required capacity of a substation supplying primarily residential load... This agrees with other studies including the work undertaken by Evans and Peak for Energex and detailed in their report "High Penetration Photovoltaic Generation and the Energex Network" dated April 2011, which recently concluded that $P V s$ provide virtually no support to residential networks at the time of peak load...

Figure 4: Output at Glenmore Park Substation

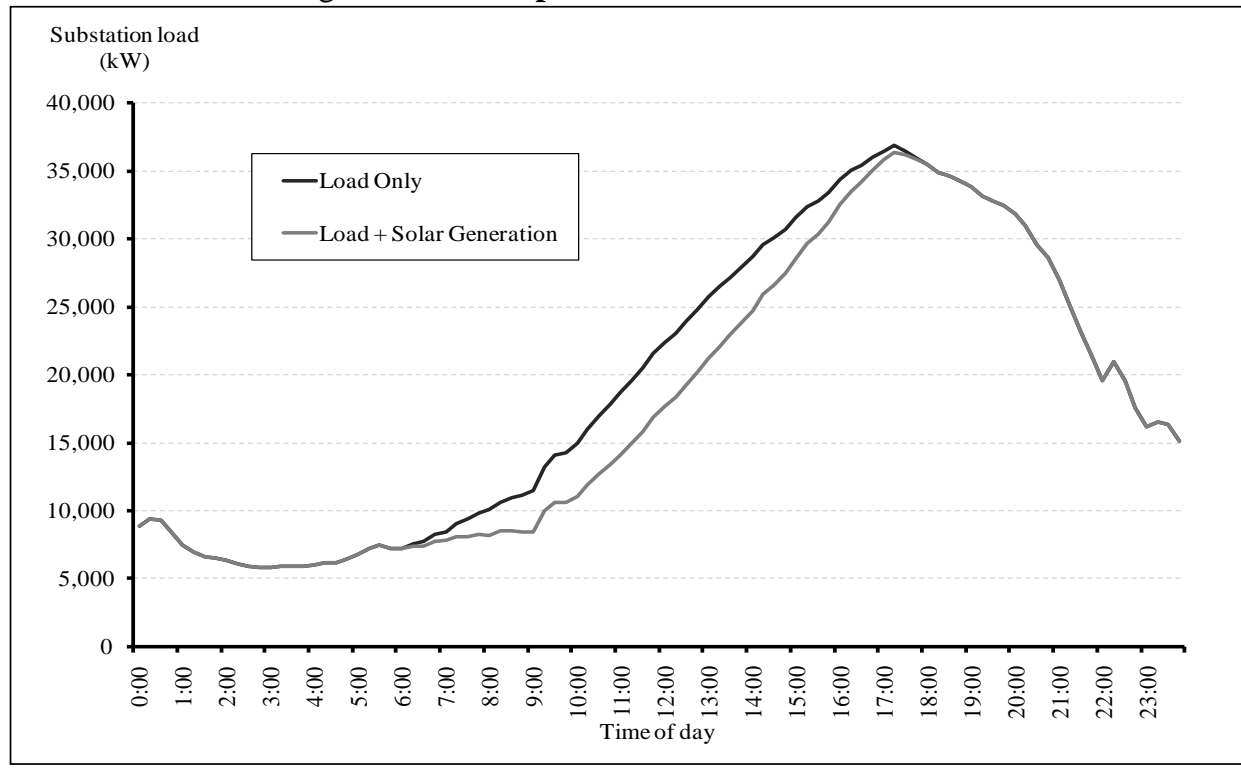

Source: Endeavour Energy (2011, p. 1)

Energex noted that output from the (then) $90 \mathrm{MW}$ of solar PV systems in south-east Queensland revealed a structural misalignment with critical peak demand (Nelson et al, 2011). A diagrammatic representation of the Energex Queensland analysis, which yields similar results to Endeavour Energy in Figure 4, has been reproduced in Appendix 1.

\subsection{Overall assessment}

Based upon an assessment against our public policy criteria, it seems clear to us that the design of Queensland's current feed-in tariff policy is sub-optimal. The policy should be redesigned to ensure that it does not result in large wealth transfers from low-income households to highincome households. And the policy should be reviewed with a degree of urgency so as to limit the intensity that the predictable boom-bust scenario is capable of graduating to for solar PV installers in Queensland. Furthermore, as in the case of New South Wales, a review should be initiated to determine whether network congestion is relieved to any significant degree by the output of household solar PV units.

\section{The 'merit order effect'}

One outcome arising from the significant winding back of premium solar feed-in tariff policies across Australia was the intensive lobbying for protection by segments of the solar PV installer industry on the basis of protecting jobs. This is common at an international level, as Clark and Pickard (2011) noted in the case of Britain when its feed-in tariff was cut by half from $43.3 \mathrm{p} / \mathrm{kWh}$ to $21 \mathrm{p} / \mathrm{kWh}$ in December $2011^{14}$, following a similar cut in Germany in the same year. At one level, the solar PV installer industry response is quite understandable because the speed and magnitude of feed-in tariff policy changes were breathtaking. A large number of installers were

${ }^{14}$ Clark and Pickard (2011) noted that if the British feed-in tariff was not restructured, the $£ 867$ million cap, which would be recovered from all electricity consumers via higher bills, would be "devoured". 
no doubt caught with excess stock, falling demand, and in many cases, financial distress or outright bankruptcy.

In the NEM, the initial response to policy changes by some solar advocates was a call for 'grid parity tariffs' (i.e. at the current retail tariff of c.\$200/MWh). However, we noted in Sections 1 and 3.3 that the predominant economic costs of the distribution network and energy retailing costs are not avoided through the deployment of solar PV units, and as such there is no obvious case in economic theory or practice for grid-parity tariffs. We also noted earlier that the most recent regulatory inquiry into the matter by IPART (2012) found the fair value of solar PV output (including its particular unique characteristics related to time of output) to be in the order of $\$ 52$ $\$ 103 / \mathrm{MWh}$ with a midpoint of $\$ 77.50 / \mathrm{MWh}$. In theory, the value of 'renewable energy' should not be ascribed to this $\$ 77.50$ 'fair value' because PV units have already received a balloon payment of Renewable Energy Certificates for its useful life upon installation via the deeming process under the Renewable Energy Target. ${ }^{15}$ However, in practice, PV units will likely receive the opportunity value of any prevailing price on $\mathrm{CO}_{2}$ emissions.

An increasingly prominent purported 'economic benefit' being promoted by some industry analysts is the impact of increased deployment of solar (and by implication, wind) resources in lowering the wholesale market price (see for example Parkinson, 2011; and Parkinson, 2012). This is known as the 'merit order effect' and was not contemplated in Nelson et al (2011), or in our Section 3 analysis.

In simple terms, the so-called 'merit-order effect' relates to an episode of wholesale price suppression that occurs when significant volumes of low marginal running cost generation (such as wind or solar PV) are added to a power system. So for example, if $1000 \mathrm{MW}$ of renewable capacity is added to a $12,000 \mathrm{MW}$ power system like Queensland, it can be expected to reduce the wholesale power price because by definition, the supply curve will shift to the right, and holding all else constant, the benefits of a lower wholesale price would accrue to consumers. ${ }^{16}$ This effect is therefore said to be an economic benefit arising as a direct result of the feed-in tariff policy, because it 'caused' the addition of 1000MW of new renewable energy capacity in the first place.

The merit order effect has a certain superficial appeal, despite the obviously erroneous nature of the concept. It has been surprisingly well documented in academic literature, dating back to at least 2008. The merit order effect is generally analysed in the context of wind turbines (Sensfuss, Ragwitz and Genoese, 2008; Poyry, 2009; Henney, 2010; Pirnia, Nathwani and Fuller, 2011; Gelabert, Labandeira and Linares, 2011; Felder, 2011) but more recently has been applied to solar PV feed-in tariffs as Parkinson (2012) observed. ${ }^{17}$ The common thematic in each of these studies, which cover Germany, Britain, Ontario, Spain, the US and Australia is that as more renewable resources are added to an existing grid, they place downward pressure on wholesale prices. None of these studies, however, conclude welfare has been enhanced. And of course, it should be obvious that the findings are not particular to renewable energy - adding a large nuclear power station or expanding a very low marginal running cost coal plant like CS Energy's 'Kogan Creek'

\footnotetext{
${ }^{15}$ To reduce transaction costs, solar PV units are able to create the stream of Renewable Energy Certificates that would ordinarily accrue over its useful life "up front". This 'deemed' stream of certificates is created upon installation, which is in turn claimed as a subsidy against the capital cost of installation.

${ }^{16}$ Of course in practice, this is erroneous because customers typically sign fixed-price term contracts ranging from 1-3 years in tenor, or remain on the default tariff, which is usually set at the long run marginal cost of supply. Retail tariffs have little direct nexus with real-time spot prices.

${ }^{17}$ Utility-scale wind farms (i.e. greater than $30 \mathrm{MW}$ ) are required to submit half-hourly generator bids to the power exchange, and in turn form part of the aggregate supply function for the purposes of centralised dispatch of the power station fleet. Utility-scale wind farms are, therefore, directly associated with the so-called merit order effect. Residential solar PV units on the other hand are not centrally dispatched, their output is revealed in the market as a reduction in the aggregate demand function and so in a strict technical sense, small-scale units do not affect the aggregate wholesale market supply curve, but an offset to the retail demand curve. However, for the purposes of our analysis in Figures 5,6 and 7, we treat all forms of renewables as if they are centrally dispatched to better illustrate the thematic behind the merit order effect since the net effect on wholesale price is identical under either method.
} 
power station in Queensland would also produce a merit order effect, even after accounting for the likely cost of $\mathrm{CO}_{2}$ emissions - commencing at $\$ 23 / \mathrm{t}$ in 2012/13.

Houthakker (1951) noted long ago that electricity tariff theory and practice is a special branch of welfare economics, and so the merit order effect is therefore best dealt with through a conventional economic analysis of its welfare impacts on producer and consumer surplus. We do this by presenting Figure 5, which establishes the form of the energy industry aggregate supply function given by the curve $(\gamma)$. This supply curve reflects the structure of the marginal running costs for a regional power station fleet comprised exclusively of thermal coal and gas plant (i.e. no renewables), spanning the operating ranges of base, intermediate, peaking and emergency peaking duties. Whether externalities arising from thermal production are taken into account is not important for our analysis, although for completeness we should assume that curve $(\gamma)$ incorporates a price on carbon. There are two demand curves, one for peak periods $\left(d_{p}\right)$ and another for off-peak periods $\left(\mathrm{d}_{\mathrm{o}}\right)$. Consumer surplus in off-peak periods is represented by the light-shaded triangle area marked $a_{0} e_{o}$ while producer surplus ${ }^{18}$ in the off-peak period is represented by the dark-shaded area $\mathrm{cp}_{o} \mathrm{e}_{\mathrm{o}}$. Similarly, producer surplus in the peak period is represented by the area $\mathrm{cp}_{\mathrm{p}} \mathrm{e}_{\mathrm{p}}$ while consumer surplus is the triangle commencing from the base line $\mathrm{p}_{\mathrm{p}} \mathrm{e}_{\mathrm{p}}$ and extending to the point at which the (truncated) peak demand curve $\mathrm{d}_{\mathrm{p}}$ meets the $\mathrm{y}-$ axis.

Figure 5: Aggregate energy industry supply and demand with no renewable resources

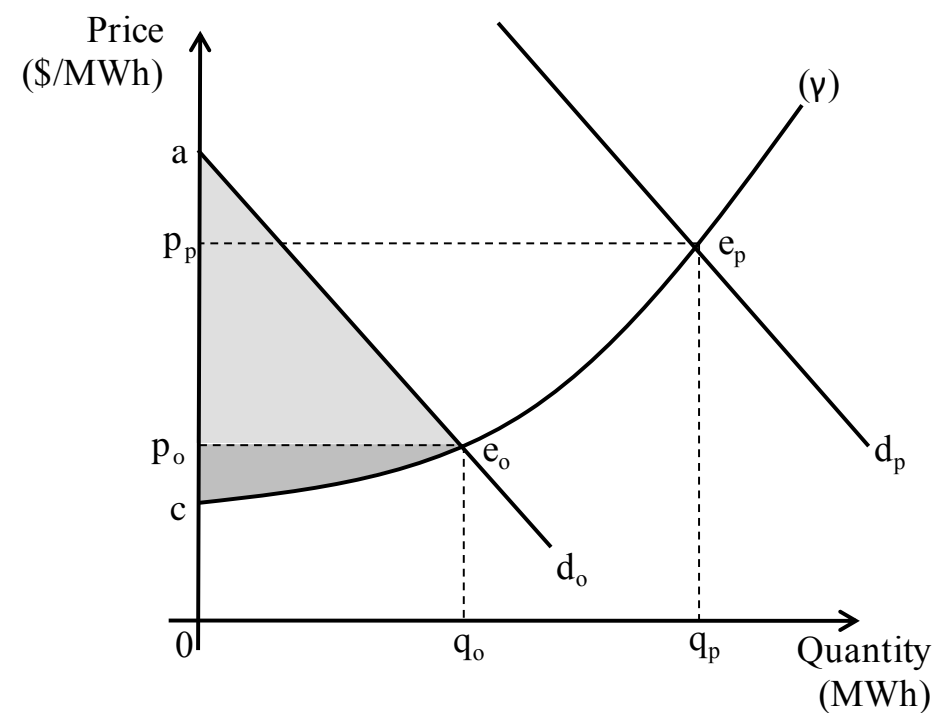

Next in Figure 6, we introduce a fleet of renewable generators, which have extremely low marginal running costs. We assume that this renewable generating capacity has been introduced into the market by policy, through a premium feed-in tariff, or some other renewable energy policy incentive mechanism. This has the effect of shifting the aggregate supply function downwards and to the right, from curve $(\gamma)$ to curve $\left(\gamma_{1}\right)$, and lowers the equilibrium clearing prices in the peak and off-peak periods, from $\mathrm{p}_{\mathrm{o}}$ to $\mathrm{p}_{\mathrm{o}}$ and $\mathrm{p}_{\mathrm{p}}$ to $\mathrm{p}_{\mathrm{p}}$, respectively.

\footnotetext{
18 This term is used here for simplicity. A more precise term would be 'producer operating profits', because the industry supply curve $\gamma$ reflects only marginal running costs and ignores generators' fixed costs. In a competitive energy-only electricity market, generators should (in theory) earn only a 'normal' profit in the long run irrespective of the relative level of their marginal running costs.
} 
Figure 6: Energy industry aggregate supply and demand including renewable resources

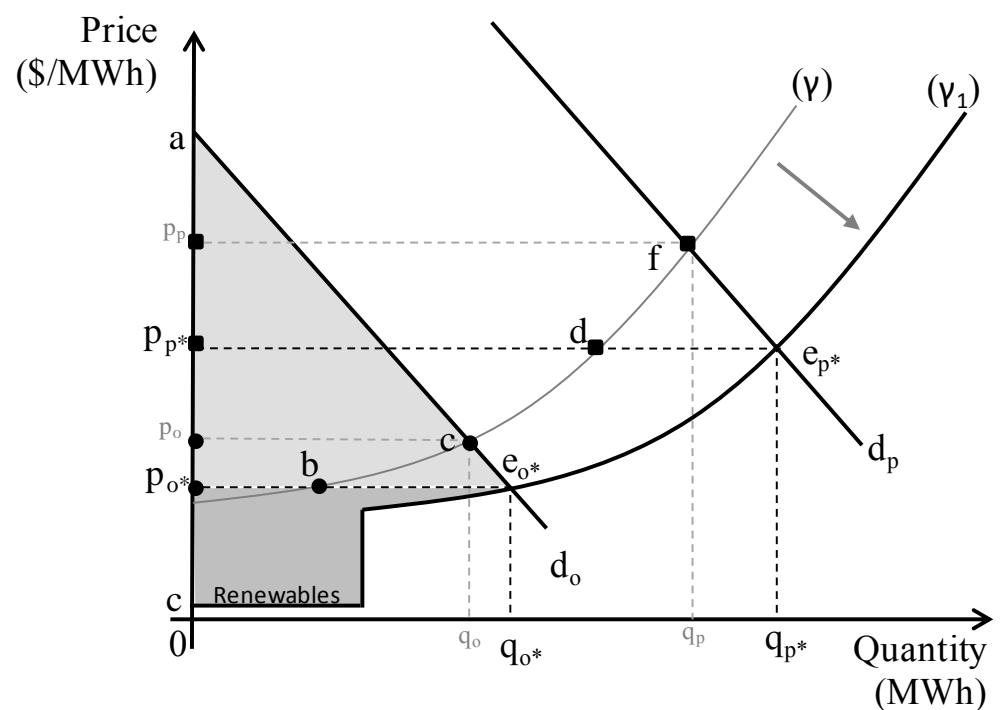

The primary result in Figure 6 is an increase in consumer surplus in both peak and off-peak periods as a result of the shift in the aggregate supply function. Consumer surplus in off-peak

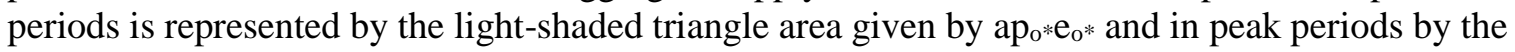
triangle commencing from the base line $\mathrm{p}_{\mathrm{p}} \mathrm{e}_{\mathrm{p}}$ and extending to the point at which the (truncated) peak demand curve $d_{p}$ meets the $y$-axis. Importantly however, a non-trivial component of the increase in consumer surplus represents nothing more than a policy-induced wealth transfer from existing electricity producers to electricity consumers. In off-peak periods, the area representing wealth transfers is given by the black dots labelled $\mathrm{p}_{\mathrm{o}} * \mathrm{bc} \mathrm{p}_{\mathrm{o}}$ and in peak periods by the area represented by the black squares labelled $\mathrm{p}_{\mathrm{p}} * \mathrm{df} \mathrm{p}_{\mathrm{p}}$. There are some apparent efficiency gains related to changes in demand in Figure 6, although electricity demand is highly inelastic in the short run, as are retail electricity tariffs, and so these efficiency gains seem to us to be quite contentious. Regardless, Figure 6 demonstrates the essence of the 'merit order effect'.

At one level, there is nothing controversial about the notion that adding more generating equipment with extremely low marginal running costs to a power system will, ceteris paribus, have a suppressing impact on wholesale prices. For example, power system simulation modelling in Simshauser (2011) using the NEMESYS Model ${ }^{19}$ demonstrates wholesale price suppression. The 3700MW South Australian power system was examined with, and without 17\% (870MW) of its energy being derived from wind generation. Wind generation has a marginal running cost of close to zero. When the power system was in equilibrium (without wind), wholesale system average cost was found to be $\$ 99.75 / \mathrm{MWh}$ and the long run marginal cost of base load thermal plant was estimated to be $\$ 75.65 / \mathrm{MWh} .{ }^{20}$ For the purposes of this article, we have made use of the South Australian NEMESYS Model results from Simshauser (2011), and in particular, the simulated half-hourly spot price outcomes. Without renewable resources, the model produced a time-weighted or base load average spot price of $\$ 75 / \mathrm{MWh}$. When we added 870MW of renewable generation to the South Australian system holding everything else constant, the base load spot price reduced from $\$ 75$ to $\$ 64 / \mathrm{MWh}$. Given short-run inelastic energy demand of $14,400 \mathrm{GWh}$, this represents an apparent gain to consumers of $\$ 155$ million in a wholesale market that has a total annual value of $\$ 1.4$ billion. This of course presumes that retail prices are as flexible and responsive as wholesale spot prices, which they are not.

${ }^{19}$ The NEMESYS Model is a dynamic, partial equilibrium model of the power system with half-hourly resolution and price formation based on a uniform, first price auction consistent with the NEM design. The model assumes perfect competition and essentially free entry to install any combination of capacity that satisfies differentiable equilibrium conditions with wind output being exogeneous to the equilibrium investment model. The NEMESYS Model has been documented extensively in Simshauser (2008), and the specific scenarios outlined above are documented in detail in (2011) and accordingly, we do not propose to reproduce them here.

${ }^{20}$ See in particular Simshauser (2011), Table 7, p.286. 
More importantly, as Simshauser (2011, p.269) noted, the direct cost of renewable resources are "unambiguously more expensive than thermal plant". And crucially, as Felder (2011) observed, system analysis based on the constructs contained in our Figures 5 and 6 alone are incomplete because they reflect short-run supply costs, not long run supply costs. Accordingly, the concept of power station development costs, having long been acknowledged as one of the most important characteristics of electricity tariff design as far back as Boiteux (1949) and Houthakker (1951), are necessarily introduced in Figure 7.

The static results presented in Figures 5 and 6 are obviously highly stylised, but most importantly, overlook the predominance of the heavy fixed costs that characterise the industry's asset stock. In Figure 7 we have removed the peak and off-peak tariffs and assume a simple average cost tariff (which simplifies the graphics considerably). Our original supply curve given by $(\gamma)$ represented the industry's real-time marginal running cost curve, and therefore ignored the critical importance of recovering the very heavy fixed costs of the industry. In Figure 7, the industry average cost function, before renewables, is introduced and given by the curve $(\delta)$. This is the benchmark for which consumer headline electricity tariffs are set against, represented by tariff $\mathrm{p}_{\mathrm{ac}}$ with quantity demanded of $\mathrm{q}_{\mathrm{ac}}$ and $\mathrm{q}_{\mathrm{o}}$ in peak and off-peak periods, respectively. When renewable energy capacity is added, the industry's real-time marginal running cost curve supply curve $(\gamma)$ shifts downwards to $\left(\gamma_{1}\right)$ as in Figure 6, but crucially, note that the long run average cost function shifts upwards, from $(\delta)$ to $\left(\delta_{1}\right)$. The reason for this is straightforward. Renewable energy resources have very low marginal running costs, but extremely high average total costs due to a predominance of fixed (capital-related) costs. Consequently, headline electricity tariffs must also shift upwards, from $\mathrm{p}_{\mathrm{ac}}$ to tariff $\mathrm{p}_{\mathrm{ac}}$.

Figure 7: Long run industry aggregate supply and demand curves with renewable resources

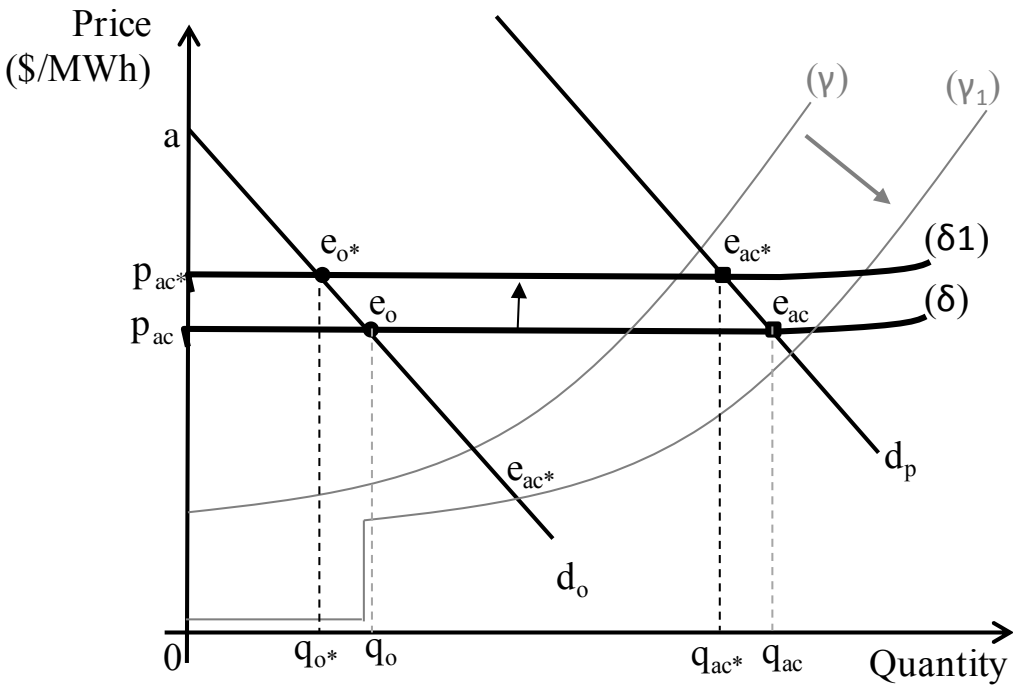

(MWh)

We noted earlier that it is uncontroversial to state that adding more low marginal running cost generating equipment to a power system will, ceteris paribus, have a 'suppressing effect' on wholesale prices in the short run. But it is equally uncontroversial to state that adding more expensive average total cost generating equipment such as renewables to a power system will have an 'impressing effect' on the overall cost to serve load, and hence headline electricity tariffs (Felder, 2011). The notion that a new entrant generator, producing a merit order effect is ipso facto welfare enhancing is, therefore, erroneous.

As noted above, power system simulation modelling in Simshauser (2011) examined the addition of $870 \mathrm{MW}$ of wind capacity to the 3700MW South Australian system, and holding all else constant, our simulation modelling resulted in spot prices dropping from $\$ 75 / \mathrm{MWh}$ to $\$ 64 / \mathrm{MWh}$ 
- producing an apparent gain of $\$ 155$ million. What that earlier analysis did not reveal was the increase in system average cost, from $\$ 99.75 / \mathrm{MWh}$ to $\$ 109.75 / \mathrm{MWh}$. Neither the drop in spot prices, nor the rise in system average cost, is at all surprising. After all, an oversupply of higher cost renewable capacity was purposefully engineered.

In Simshauser (2011), simulation modelling focused on changes in capacity over the long run, thus allowing the system to dynamically adjust to a more appropriate equilibrium position rather than deliberately engineering a short run oversupply. The key finding of the long run simulation was that the $870 \mathrm{MW}$ of intermittent wind generation made a contribution to system reliability, albeit at a discounted rate, and so a future $300 \mathrm{MW}$ base load power plant was able to be avoided. ${ }^{21}$ Following a comparative reduction in base load thermal plant, long run modelling produced a time-weighted or base load average annual spot price for the wind scenario of $\$ 76 / \mathrm{MWh}$, virtually the same as the $\$ 75 / \mathrm{MWh}$ thermal plant scenario. As a result, in the long run any wholesale price impacts of the merit order effect are 'neutralised'. Conversely, average system costs demonstrably increased because, as noted earlier, renewable resources are unambiguously more expensive than thermal plant. Although a base load plant had been avoided, system average costs in the South Australian grid increased by about $\$ 8 / \mathrm{MWh}$, from $\$ 99.75 / \mathrm{MWh}$ to $\$ 107.84 / \mathrm{MWh}$. Total system costs had therefore increased by $\$ 116$ million per annum (Simshauser, 2011). ${ }^{22}$

So, with the merit order effect, while there may well be an apparent short run wholesale market price reduction, this can only be transient. Tariff reductions would accrue to consumers only if an oversupply persisted well into the future, and only if headline electricity tariffs deviated substantially from industry long run marginal cost - all of which would represent courageous assumptions at best because if this occurred in fact, it would raise tangential doubts about the entire sustainability of the industry - its institutional arrangements and above all, renewable resource policies settings. In the long-run, the effects of introducing high average cost, low marginal running cost generation cannot be 'price-beneficial' to consumers. On the contrary, headline electricity tariffs can be reasonably expected to increase from the status quo. As Felder (2011, pp.34-35) noted:

"The price-suppression [merit-order] effect is typically raised to support clean energy resource policies... although it has also been used to support transmission and nuclear power investments. It is used most forcefully to justify "out-of-market" investments, such as solar and wind, whose costs are higher than the revenue that they would obtain over their operating lives. Imagine, however, if all electricity was provided by out-of-market technologies. Wholesale energy prices would be near zero, yet consumer electricity costs would increase to cover the additional costs of these technologies, thereby indicating that there was something amiss. How can out-of-market investments decrease the price of electricity for consumers?"

The most important finding from our analysis is that any short run reduction in wholesale market prices arising from the merit order effect principally result in a wealth transfer from all existing market-facing generators, both thermal and renewable ${ }^{23}$, to electricity consumers. If a merit order effect occurred due to natural market disruption events such as the entry of a new renewable or low emission technology with lower marginal running costs and lower total costs than incumbent generators, it would produce an unambiguous improvement in welfare. However, with premium

${ }^{21}$ See especially Figure 6 and Table 8 in Simshauser (2011, pp 285-286).

${ }^{22}$ The Australian Energy Market Commission (AEMC, 2011, p.25) considered the impact of the merit order effect in relation to adoption of renewable energy portfolio standards and concluded that ...wholesale prices are depressed by an increased volume of renewable generation capacity which is able to bid in a manner to ensure dispatch... [however] lower wholesale prices [also] means that renewable generators become more reliant on [Renewable Energy Certificate] revenue to ensure their profitability, which leads to an increase in the price [of Certificates]...

${ }^{23}$ Any short run reduction in wholesale market prices will adversely impact renewable generators with merchant exposures, or for those renewable generators that have been fully contracted, the holders of the Power Purchase Agreements will be adversely affected. 
feed-in tariffs the 'merit order effect' is being orchestrated by public policy, and the policy instrument is simultaneously distorting the operation of an otherwise efficient economic market framework. The notion that suppressing wholesale prices with a sub-economic technology and distorting an otherwise properly functioning competitive market is somehow a desirable outcome is simply not correct, and no policymaker ought to pursue such an option in practice given the long run risks this would inevitably place on the security and cost of electricity supplies. The pursuit of such policy objectives has been rejected in theory and in practice for several reasons:

- Developers of new generation capacity will be more likely to hesitate investing the requisite (and very substantial) debt and equity capital in markets where a distinct government policy intervention has resulted in non-trivial reductions in operating profits for existing participants, particularly in light of the substantial sunk costs that need to be incurred by generation investors. Simshauser and Nelson (2012) demonstrated this concept comprehensively in relation to transitional assistance for emissions intensive coal-fired generators as a result of the impacts of carbon pricing. The theory is equally applicable here. Investors in generating plant, and Power Purchase Agreement (PPA) underwriters who facilitate such investments, will be reluctant to act for all forms of generation capacity (including utility-scale renewable resources) if government policy is seen to be reducing the profitability of incumbent plant or forward PPA contracts unnecessarily.

- While small-scale renewable resources may recover their costs through subsidised feed-in tariffs, new thermal plant will only be built where prices in the wholesale market are expected to cover the costs. Simshauser (2011) and our modelling results above demonstrated that over the long-run, price suppression impacts diminish. Under a worst case scenario where thermal plant investments are delayed excessively due to excess feed-in tariff capacity, wholesale prices may eventually 'snap' when new thermal investment becomes vital to maintain security of supply. The extent of market volatility that comes with such a scenario is not in the interests of consumers, producers or investors. Gelabert, Labandeira and Linares (2011, p. S65) concisely summarised this argument when they noted that "the decreasing trend in electricity prices may be incompatible with the necessary remuneration of non-renewable resources".

- At the extreme, a long run merit order effect deliberately engineered by excessive premium feed-in tariffs could make a robust energy market model collapse. For example, Roam (2010) completed an extensive study examining transmission congestion and the deployment of increasing levels of renewable energy. The Roam study concluded that a short run merit-order effect existed, but identified a genuine market tipping point something which Green and Vasilakos (2009), Poyry (2009) and Henney (2010) also identified in the case of the British energy market - if renewable energy capacity dominates too much of the aggregate supply function through subsidies, and spot prices are sustained below total plant costs even in the long run, the entry of requisite balancing plant becomes intractable. In the short and intermediate run, such a scenario poses no insurmountable threat to the physical operation of the grid. Over the long run given gradual growth in demand, the entire model of bilateral energy markets can also become completely intractable. Given a choice between the so-called 'merit order effect of subsidised solar PV units' versus a robust competitive market model that delivers security of energy supply, policymakers will always opt for security of energy supply as the dominant policy objective function.

In summary then, a merit order effect exists, and leads to price suppression in wholesale energy markets where large volumes of renewable capacity are installed. But economic benefits associated with 'premium' feed-in tariffs are difficult to trace. Unless the merit order effect is 
accompanied by a genuine reduction in the total unit cost of power (including a fair value for externalities), the result is nothing more than a short term wealth transfer from existing electricity producers to consumers and a long run increase in overall costs leading to a loss of consumer (or taxpayer) welfare. And the merit order effect is transient because "the reduction in prices will in turn result in lower investments and therefore higher prices in future periods" (Gelabert,

Labandeira and Linares 2011, p. S65). This is not to say that policy makers should not introduce policies aimed at increasing renewable energy policy capacity and production. There are many sound economic and environmental reasons for introducing renewable energy policies - but the merit order effect is not welfare enhancing, and is therefore not one of them.

\section{Policy Implications and Concluding Remarks}

Since 2009, there has been a proliferation of premium feed-in tariff policies developed by State and Territory governments within Australia aimed at stimulating investment in small-scale residential solar PV installations. These policies have had a dramatic impact on installation rates of solar PV units. Our analysis revealed that the growth in the installed capacity of solar PV units reached more than $10,000 \%$ in just a few years. However, most state governments have either abolished their premium feed-in tariff policies, or have wound them back substantially. Queensland has retained its premium feed-in tariff, and we would therefore expect solar PV sellers to focus their marketing efforts on its' residents given that the existing policy provides the last 'premium' subsidy.

Of course, even if the policy in Queensland is wound back, existing solar PV installations will retain access to the premium feed-in tariff. To eliminate such a right would be an act of retrospective policymaking. The consequence is that the cost of the scheme and its adverse welfare effects on low income households has been locked-in for the entire policy tenor. In the case of Queensland, this is surprisingly long, out to 2028 under the Electricity Act 1994. While this is a poor policy outcome, ongoing loss of welfare is relatively small (as the costs are spread across the entire population) when compared with the welfare impacts associated with retrospective policy making.

As domestic policies have been wound back, some proponents of solar PV feed-in tariff policies have insisted that research such as Nelson Simshauser and Kelley (2011) ignored an important economic benefit, namely the 'merit order effect' - where very low short-run marginal cost capacity (e.g. solar PV) is added to a power system thereby suppressing wholesale energy prices. In this article, we demonstrated that the merit order effect is a real phenomenon in energy markets. However, our analysis and those from international studies are also clear that while the merit order effect may well be real in wholesale energy markets, any consumer benefit are at best transient and above all, the overall effect on welfare is adverse. The notion that suppressing wholesale prices and adversely affecting the profitability of existing producers by subsidising a sub-economic technology through a premium feed-in tariff, and distorting an otherwise properly functioning competitive market is somehow a desirable policy outcome is simply not correct.

In assessing efficiency and effectiveness of the only remaining original premium feed-in tariff policy still in place, we used criteria based on whether policy funding is progressive or regressive; the ability of the policy to avoid pro-cyclical industry development; and whether the policy captures distributed generation benefits. Our analysis found that the Queensland policy is significantly regressive in nature, with the effective rate of taxation paid by low income households being 3.4 times higher than high income households. We also found that the Queensland policy is likely to be pro-cyclical rather than long-run sustainable based on international experience, and that network benefits are at best likely to be trivial and are not supported by any compelling evidence to date. 
Politicians in all Australian States and from all political persuasions were initially eager to support feed-in tariff policies. Queensland was no different when its Clean Energy Bill 2008 comprising the feed-in tariff policy was introduced into parliament. Hansard demonstrates that all sides of politics were eager to support the policy, and this was typical of all National Electricity Market jurisdictions ${ }^{24}$ Policymakers around the country have introduced these policies without understanding the regressive wealth transfers that almost always result when the electricity industry is used as a taxation collection mechanism. The position that the energy industry is left in today as a result of such policies was best summarised by the Australian Capital Territory Chief Minister who remarked on their own feed-in tariff arrangements - "the whole episode has demonstrated the folly of making policy on the run” (Gallagher, 2011).

In our view, Queensland policymakers should conduct a review of current policy settings and ensure that the feed-in tariff policy is reassessed ${ }^{25}$, and ideally, redesigned in a way that satisfies the criteria of (1) non-regressive incidence of the tax burden, (2) anti-cyclical industry development, and (3) from a valuation perspective, tariffs set at a sustainable level. This is necessary to ensure that long-term policy is established in a way that reduces unnecessary wealth transfers while still increasing the proportion of renewable energy in Australia's energy mix. Above all, feed-in tariff policies in Australia needs to be considered, and based, on evidence.

\section{References}

Australian Energy Market Commission, (2011), Impact of the enhanced Renewable Energy Target on energy markets, Australian Energy Market Commission Publication, Sydney

Boiteux, M. (1949), "La tarification des demandes en pointe: Application de la theorie de la vente au cout marginal”, Revue Generale de l'Electricite, Translated by H. Izzard in Journal of Business, Boiteux, M. 1960, 'Peak load pricing', Journal of Business, 33(2): 157-80.

CEC: Clean Energy Council, (2011), Clean Energy Australia Report 2011, Clean Energy Council

Publication, Melbourne

Clark, P. and Pickard, J. (2011), "Solar chiefs threaten legal action”, Financial Times, 31 October 2011.

Endeavour Energy, (2011), "Review of solar feed-in tariffs", Submission to IPART, Available at: http://www.ipart.nsw.gov.au/files/19613bc0-e7d7-4650-8f48-9f910118dd86/Submission_-_Solar_feedin_tariffs_-_Endeavour_Energy_-_12_September_2011_-_Website_version.pdf, Accesse- on 17 January 2012

Energex, (2010), 2010 Queensland Household Energy Survey, Brisbane

ESAA: Energy Supply Association of Australia (2010), Electricity Gas Australia, ESAA Publication, Melbourne

First Solar (2011), First Solar 2012 Guidance, Presentation to Financial Markets, December 14, 2011

Felder, F. (2011), "Examining electricity price suppression due to renewable resources and other grid investments," The Electricity Journal, Vol. 4, No. 4, pp. 34-46.

Felder, F. (2010), "The practical equity implications of advanced metering infrastructure", The Electricity Journal, 23(6): 56-64.

Gelabert, L., Labandeira. X, and Linares, P. (2011), "An ex-post analysis of the effect of renewables and cogeneration on Spanish electricity prices", Energy Economics, Vol. 33, Supplement 1, S59-65

\footnotetext{
${ }^{24}$ See Hansard discussion at: http://www.parliament.qld.gov.au/documents/hansard/2008/2008_05_13_WEEKLY.pdf, accessed on 20 January 2012

25 Adjustments to policy should not be undertaken in a way that undermines investor confidence. Accordingly, a fourth criteria could be used: avoiding regulatory risk by continuing to honour payments to existing solar PV installations.
} 
Gallagher, K. (2011), "Feed-in tariff scheme closes", Media Release, Available at: http://www.environment.act.gov.au/_data/assets/pdf_file/0003/229233/110713_CM__FIT_Scheme_Closes.pdf, Accessed on 17 January 2012

Houthakker, H. 1951, "Electricity tariffs in theory and practice", The Economic Journal, 61(241): 1-25.

IPART: Independent Pricing and Regulatory Tribunal (2012), "Solar feed-in tariffs: setting a faor and reasonable value for electricity generated by small-scale solar PV units in NSW", IPART Publication, Sydney.

IPART: Independent Pricing and Regulatory Tribunal (2010), "2010 Household Survey of Electricity, Water and Gas Usage - Sydney, Blue Mountains and the Illawarra", IPART Publication, Sydney

Nelson, J. (2011) "Sustainability and feasibility of Project Financing a Merchant Power investment in Queensland's energy market", Honours thesis, Griffith University, Brisbane/

Nelson, T., Simshauser, P. and Kelly, S. (2011) "Australian residential solar Feed-in Tariffs: industry stimulus or regressive form of taxation?", Economic Analysis and Policy, Vol. 41 No. 2, 113-129

Nelson, T., Kelley, S., Orton, F., and Simshauser, P., (2010), "Delayed carbon policy certainty and electricity prices in Australia", Economic Papers, 29(4): 446-465

O'Farrell, B, (2011), Reference to IPART under s9 of the IPART Act, http://www.ipart.nsw.gov.au/files/110a13af-52db-4b86-a65e-9fbe00c593b3/Terms_of_Reference__Solar_Feed_in_Tariffs_-_4_August_2011_-_Website_version.pdf, accessed on 20 January 2012

Pirnia, M., Nathwani, J, and Fuller, D, (2011), "Ontario feed-in tariffs: system planning implications and impacts on social welfare", The Electricity Journal, Vol.24 (8), pp. 18-28

Pöyry for the European Wind Energy Association, (2010), Wind Energy and Electricity Prices Exploring the 'merit order effect, European Wind Energy Association Publication

Parkinson, G, (2012), "Merit order: How solar FiTs could cut energy bills for all”, REneweconomy, http://reneweconomy.com.au/2012/merit-order-how-solar-fits-could-cut-energy-bills-for-all, accessed on 6 February 2012

Parkinson, G, (2011), "Why big energy wants to kill the RET”, Climate Spectator, http://www.climatespectator.com.au/commentary/why-big-energy-wants-kill-lret, accessed on 12 January 2012

ROAM Consulting, (2010), Transmission congestion and renewable generation, a report to the Clean Energy Council, available at: http://www.cleanenergycouncil.org.au/dms/cec/reports/2010/TransmissionCongestion-and-Renewable-

Generation/Transmission\%20Congestion\%20and\%20Renewable\%20Generation.pdf, accessed 23 January 2012

Sensfuss, F., Ragwitz, M, and Genoese, M. (2008), "The merit-order effect: A detailed analysis of the price effect of renewable electricity generation on spot market prices in Germany", Energy Policy, Vol. 36, pp. 3086- 3094

Simshauser, P. and Nelson, T. (2012), "The second-round effects of carbon taxes on power project finance", Journal of Financial Economic Policy, 4(2): article in-press

Simshauser, P., Nelson, T. and Doan, T., (2011a) “The Boomerang Paradox Part 1: how a nation's wealth is creating fuel poverty", The Electricity Journal, 24(1): 72-91.

Simshauser, P., Nelson, T. and Doan, T., (2011b) “The Boomerang Paradox Part 2: how a nation's wealth is creating fuel poverty", The Electricity Journal, 24(2): 63-75. 
Page 22 
Appendix 1: Solar PV output vs. day of peak demand in SE QLD (15 Feb 2010)

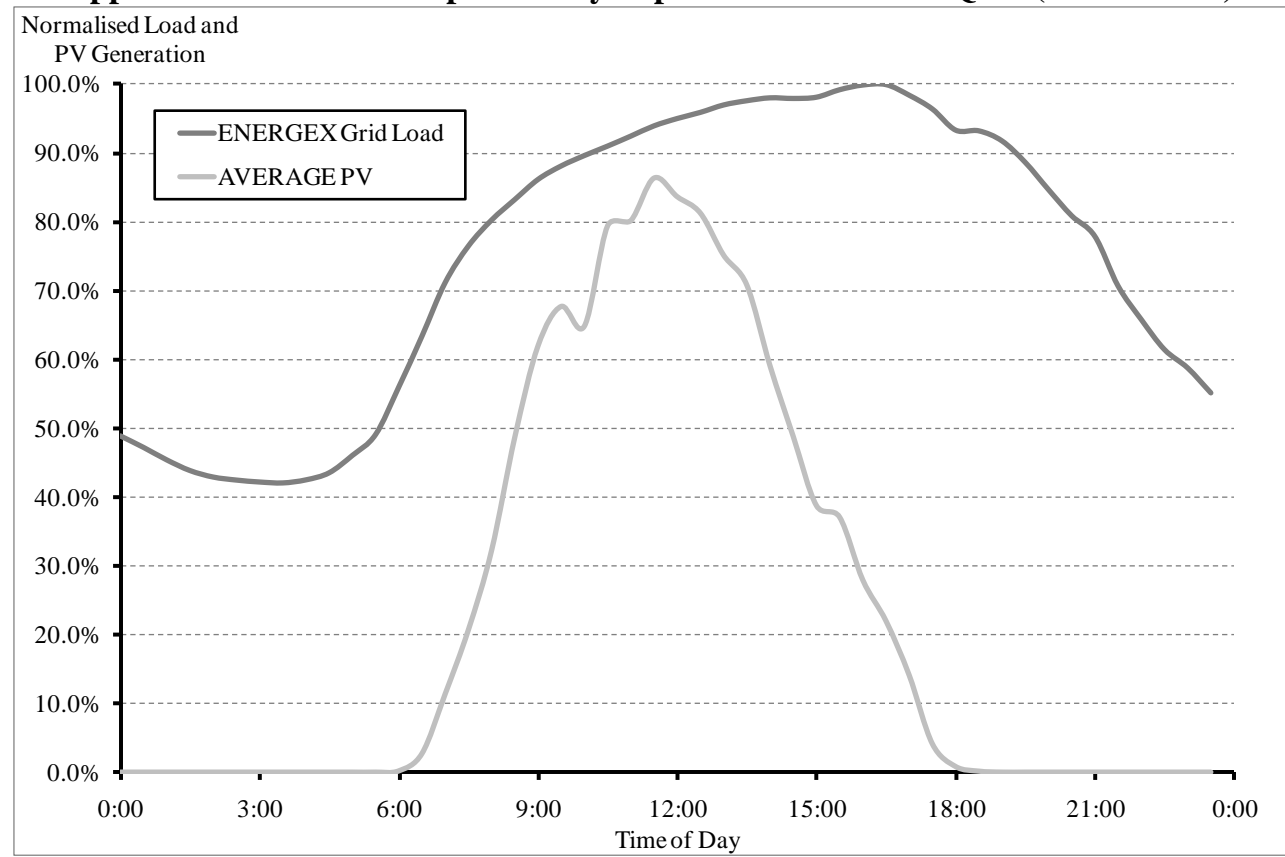

Source: Nelson et al (2011) 